\title{
A festa de boi-bumbá em Parintins: tradição e identidade cultural
}

\section{Raimundo Dejard Vieira Filho*}

Resumo: O artigo desenvolve a tese de que a força atrativa e aglutinadora do boi de Parintins não vem apenas da forma apoteótica e brilhante de sua apresentação, mas sobretudo do ethos cultural de seus brincantes. A tensão entre tradição e inovação é o fio condutor do trabalho, captando a compreensão do processo histórico-cultural que engendra novas configurações expressas em reelaborações e ressignificações da identidade cultural.

Palavras-chave: cultura popular, tradição, modernidade e identidade regional.

Abstract: The article develops the thesis that attractive power of "boi" from Parintins does not come only from apotheosis and such a great form of its performance, but also from cultural ethos of its dancers. What makes it a suitable work is a sense between tradition and innovation, which involves comprehension of historical and cultural process that comes into the cultural identity.

Keywords: popular culture, tradition, modernity and regional identity.

Ta cidade de Parintins existiram vários bois-bumbás, como o 1 Campineiro, o Corre-Campo, e outros, mas só o Caprichoso e o Garantido conseguiram sobreviver diante do processo de urbanização e crescimento da cidade, durante o século XX. São 88 anos de História, onde esses dois bois são o brinquedo de S. João dessa comunidade. Nessa trajetória, pode-se distinguir dois momentos bem diferenciados: o boi que brincava nas ruas, em frente das casas e nos quintais; e o boi participando do Festival Folclórico de Parintins, hoje um megaespetáculo na arena do Bumbódromo.

\footnotetext{
*Bacharel em Ciências Sociais, professor das Faculdades Objetivo e mestrando do Programa de Pós-Graduação Natureza e Cultura na Amazônia da Universidade Federal do Amazonas.
} 
Qual a relação existente entre esses dois momentos? Como se alimenta um do outro? Quais os fatores que impulsionaram o processo de transformação da brincadeira? Quais os elementos que consolidaram o sucesso da festa? Como, a partir do fenômeno do boi, se pode perceber o processo de formação de uma identidade cultural regional? Neste artigo pretendo iniciar a discussão sobre alguns desses pontos.

Cada povo constrói sua própria cultura a partir de suas próprias particularidades e singularidades, fruto de uma interação entre a comunidade, a natureza e o mundo externo, que vão influenciar este desenvolvimento, pois a cultura é o modo de agir, sentir, pensar de uma comunidade. São valores, gestos, atitudes, ações carregadas de significados e sentidos. A cultura está na base da comunicação entre as pessoas, e é ela que dá sentido à vida da comunidade.

Em Parintins, nas primeiras décadas do século XX, os bumbás Caprichoso e Garantido se diferenciam dos outros bumbás pelo fato de criarem uma relação mais profunda e íntima com a população. Já nascem rivais, e dividem a cidade em duas metades antagônicas. Os dois bumbás, através das décadas seguintes, se transformarão em canais, onde as classes populares poderão exprimir seus problemas, anseios e sonhos.

O bumba-meu-boi do Nordeste, chegando à Amazônia, muda de nome e é chamado de boi-bumbá. Sofre impacto das culturas das populações aqui existentes, como a dos caboclos e dos índios, marcados pela natureza peculiar que os envolve. Em Parintins, desde o início a brincadeira de boi exerce uma intensa força criadora, e seus primeiros donos, tiradores de versos, padrinhos e brincantes, com seus atos, gestos, dedicação, amor e criatividade ajudaram a criar o ethos cultural dos bois Garantido e Caprichoso. O antropólogo Darcy Ribeiro define ethos cultural como a expressão da cultura e identidade de um povo, que engloba "a linguagem, o saber, a mitologia, a religião, a magia, as artes, os corpos de valores éticos, e a integração de todos eles em um ethos, que é a concepção de cada povo sobre si mesmo em face dos demais" (1996, p. 142).

Quando o boi saía às ruas, ou se apresentava em seus quintais, era o momento de tirar versos e neles estavam embutidas as diversas experiências da comunidade, os seus valores, crenças e percepção da natureza. Era uma forma de socialização, de humanização e de registrar os fenômenos da natureza e da sociedade em que viviam. 
Os bumbás de Parintins exprimiam a estrutura da sociedade da época. A maioria dos brincantes vinha das classes mais pobres da população, mas a brincadeira era fortemente apoiada pelas classes abastadas da cidade. Os bumbás sempre se identificaram com a população inteira, desempenhando um papel de hegemonia cultural dentro da sociedade.

Parintins é uma ilha situada no meio das matas e rios da Amazônia. Sua população é síntese de uma miscigenação entre portugueses e índios - Aratu, Apocuitara, Yara, Godui, Curiatós (Cérqua, 1980) -, que depois recebeu uma corrente migratória de nordestinos, japoneses, judeus, italianos e outros. Na economia, passou por vários surtos de desenvolvimento como o do cacau, da juta, e, ultimamente, da pecuária e da pesca. Todos estes fatores contribuíram para formar o caráter aberto às inovações do povo parintinense.

Com a implantação da Zona Franca de Manaus, há uma mudança na reestruturação produtiva da economia amazonense, face ao processo de globalização. Assim, intensifica-se o êxodo rural e o interior ficou ainda mais pobre e isolado. Parintins não foge à regra. Na década de 60, é decretada a falência da Fabril Juta, e não apareceu outro produto que a pudesse substituir. Dentro deste contexto, o Festival Folclórico de Parintins começa a abrir-se como nova perspectiva econômica para o município.

Sustento que a força atrativa e aglutinadora que vem do Festival não está apenas na forma apoteótica e brilhante de se apresentar na arena do Bumbódromo, mas, sobretudo, vem do ethos cultural criado pelos seus brincantes, que foi se formando no século XX. Como exemplo, cito um verso da vasta obra de Raimundinho Dutra, compositor do lado do Caprichoso, que tira versos e compõe toadas desde 1930. Ele criou termos que foram cantados por gerações inteiras que depois os autores modernos usaram em uma nova roupagem. Em 1944, escreveu:

Balanceou, balanceou, eu quero ver balancear

Boi Caprichoso, boi campeão da terra,

Sua marujada de guerra.

Por isso é considerado o vencedor.

Na ilha Tupinambarana é o rei, sim, senhor...

As expressões como "balancear", "campeão da terra”, "marujada de guerra”, "vencedor" são usadas amplamente pelos novos autores numa carga de simbolismo muito forte ligado à tradição. 
O binômio tradição/inovação está sempre presente na experiência humana e, por extensão, na vida parintinense. Vários autores conceituam tradição como processo de sedimentação de valores e crenças, forma de organização de uma cultura, que se transmite de geração em geração.

Nestes 88 anos de existência, os bumbás Caprichoso e Garantido sofreram vários processos de mudança, acréscimos, transformações e redefinições para internalizarem as influências do novo espaço em que estavam inseridos: a Amazônia. É na década de 60 que acontece paulatinamente a criação do Festival Folclórico de Parintins, com o boi-espetáculo apresentado na arena.

São elementos antigos, que entram em confronto com os novos elementos, e depois se fundem numa síntese que liga presente, passado e futuro.

A tradição não precisa ser necessariamente muito remota e antiga, mas, de acordo com as transformações socioeconômicas, nascem novas necessidades e novas tradições aparecem, "inventadas". Essas tradições são inculcadas na mente das pessoas pela tática de repetição, em rituais simbólicos, que revivem santos e heróis do passado. As tradições "inventadas", segundo Hobsbawn e Ranger, "são reações a situações novas, que ou assumem formas de referência a situações anteriores, ou se estabelecem em seu próprio passado através da repetição quase obrigatória” (1997, p. 9-14).

Das transformações ocorridas no boi de Parintins, só adquiriram legitimidade na comunidade aquelas com profundas raízes na tradição. Essa é a tensão, esse diálogo entre o novo e o velho, que é responsável, em grande parte, pela vitalidade da festa. Tomemos como exemplo a figura da mulher, que no início era proibida de brincar no boi. À medida que a sociedade foi mudando seus valores em relação à condição da mulher, esta foi se inserindo e conquistando seu espaço na brincadeira. Curioso é que já no tempo dos festivais, década de 70 e 80, vários personagens de figuras femininas nasceram e desempenharam por um momento um fascínio, depois desapareceram porque não tinham relação com a tradição. Entre outros, estão a Rainha da fazenda, a Princesa da fazenda, a Rainha da pecuária, a Miss do boi, etc. Estes itens foram transformados em Sinhazinha da fazenda, Cunhã-Poranga, Rainha do Folclore e Porta-Estandarte.

O conceito de tradição nos remete à questão da identidade cultural, pois todo o processo criativo dos bois-bumbás Caprichoso e Garantido contribui para a construção de uma identidade regional amazônica. 
A identidade cultural tem uma relação com os fenômenos fundadores de uma comunidade e a apropriação de um território por um povo, e se constrói e se reconstrói a partir de uma intensa interação entre os indivíduos de uma região e o meio ambiente que os envolve. Segundo o antropólogo Roberto Cardoso de Oliveira, "a mesma cultura sendo comungada por todos, é o ponto central da compreensão de uma identidade cultural” (1999, p. 2).

Nas diversas linguagens transmitidas nas festas dos bois em Parintins, percebe-se uma valorização dos elementos regionais. A meu ver, há uma reinterpretação do modo de viver do caboclo e do índio, imersos na natureza amazônica, diante da multiculturalidade da realidade brasileira, com um propósito de reafirmar uma diferença em relação ao nacional, de afirmar sua própria particularidade. Neste sentido, as diversas expressões artísticas apresentadas são densas de significado e conteúdos regionais que dificultam a absorção pelo restante do Brasil, por chegar a se contrapor a uma visão de nação construída por outros centros culturais do país.

Através das alegorias do boi se pensa a Amazônia, retomando seu passado, refletindo o presente e projetando o futuro, isto é, compreendendo o que fizeram com a região, mas, sobretudo, o que vamos fazer daquilo que fizeram com a Amazônia. Na festa do boi, há uma afirmação da cultura regional, tomando consciência de suas próprias maneiras de sentir, pensar e agir em relação aos outros, num processo dialético de identidade e alteridade. Como já afirmei, uma identidade cultural é dinâmica, constrói-se e se reconstrói em diversos momentos históricos e não se reduz apenas a uma única dimensão. É um sentimento de fazer parte, que no senso comum chamamos de "raízes de um povo”, ou, em outras palavras, é a própria essência de um povo.

O boi de Parintins valorizou a cultura cabocla e indígena, que antes era motivo de vergonha e discriminação pelas ideologias da história oficial.

A partir da análise de tradição e de identidade cultural, pode-se questionar como a festa do boi de Parintins se insere numa discussão sobre regional/nacional, local/mundial no processo de globalização. As culturas locais e regionais se inserem num processo mais amplo de divulgação, adaptando suas particularidades em linguagens globais. Há um processo de desenraizamento de coisas e idéias, simultaneamente com um processo de troca, de intercâmbio e enriquecimento mútuo.

Quando elementos de diversas culturas do globo se encontram, dialogam e permutam, há o fenômeno de reafirmação das singularidades e das originali- 


\section{Raimundo Dejard Vieira Filho}

dades. A reafirmação de identidade cultural é um refúgio ao processo de globalização.

Segundo o sociólogo Octavio Ianni, hoje no mundo há um processo intrincado de transculturação envolvendo a ocidentalização, a orientalização, a africanização e a indigenização. No boi de Parintins, a partir da década de 90, o índio passou a ter papel de destaque nas toadas, nas alegorias, nos rituais. Na história oficial, o índio foi primitivo e escravo; no novo auto do boi, ele é ator principal na construção da identidade amazônica, apontando caminhos por onde a sociedade civil e o Estado deverão percorrer, no sentido de reconhecer sua dignidade e cultura.

O antropólogo Renato Ortiz afirma que numa cultura mundializada "há uma relação entre uma suposta cultura global nascente com as culturas locais, numa espécie de retroalimentação recíproca” (2000, p. 27).

O boi de Parintins se mundializa na medida em que absorve toda a técnica que a modernidade oferece e insere no seu espetáculo e, ao mesmo tempo, influencia outras manifestações culturais, regionais e nacionais. Na própria dinâmica intrínseca das culturas existe uma capacidade de reelaborar e reinterpretar valores culturais recebidos de fora. A inovação seria justamente a reelaboração de valores próprios combinados com elementos de fora.

Concluo afirmando que o boi de Parintins recria a Amazônia, fazendo em seu espetáculo uma nova interpretação dos mitos, lendas e história. A cultura regional se revitaliza e contribui para a construção de uma identidade amazônica em diálogo com a cultura mundial. Lá o tradicional e o moderno dialogam continuamente e, ao mesmo tempo, trazem nas suas concretizações uma relação tensa e complexa.

Uma dessa relações é o fato do Festival ser realizado e produzido numa cidade do interior do Amazonas, onde os valores tradicionais, como a religião, a amizade, a família, o folclore etc. ainda são cultivados. Ao mesmo tempo, na produção do espetáculo está contido todo o processo de racionalização e sistematização que o mundo moderno oferece. Isto é fator de atração da festa, pois o festival, valorizando os mitos, a religião e a arte como formas de interpretar a realidade, transforma-se em um dos caminhos para o reencantamento do mundo.

Percebo que na manifestação cultural do boi de Parintins existem dois movimentos simultâneos. O primeiro é a busca de inovações respeitando os 
padrões tradicionais, e o segundo é o retorno aos conteúdos tradicionais sem perder o que foi conquistado nas formas modernas.

Hoje o Festival não é mais uma simples repetição dos rituais tradicionais, e sim um espaço onde a comunidade, através de seus artistas, faz suas reivindicações, cria novas visões de mundo e novas utopias para Amazônia.

\section{Referências bibliográficas}

CANCLINI, Nestor Garcia (1999). Consumidores e cidadãos. Conflitos multiculturais da globalização. $4^{\mathrm{a}}$ ed. Rio de Janeiro: UFRJ.

CARDOSO DE OLIVEIRA, Roberto (1999). Identidade, etnia e estrutura social. São Paulo: Pioneira.

CÉRQUA, Dom Arcângelo (1980). Clarões de fé no Médio Amazonas. Manaus: Imprensa Oficial do Estado do Amazonas.

CUCHE, Denys (1999). A noção de cultura nas Ciências Sociais. Bauru: Edusc.

DUTRA, Raimundinho. Trajetória de Raimundinho Dutra no boi-bumbá Caprichoso. (Mimeo).

HOBSBAWN, Eric e RANGER, Terence (1997). A invenção das tradições. São Paulo: Paz e Terra.

IANNI, Octavio (1997). Globalização e transculturação. Campinas: Tech/Unicamp, abril (Primeira versão).

OLIVEN, Ruben George (1992). A parte e o todo. A diversidade cultural no Brasil-Nação. Petrópolis: Vozes.

ORTIZ, Renato (2000). Mundialização e cultura. São Paulo: Brasiliense.

. (1986). Cultura brasileira e identidade nacional. São Paulo: Brasiliense.

RIBEIRO, Darcy (1996). Teoria do Brasil. Rio de Janeiro: Civilização Brasileira.

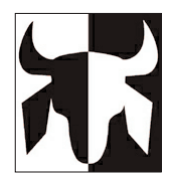

